ACS Appl Mater Interfaces. 2016 March 09; 8(9): 5917-5928. doi:10.1021/acsami.6b00294.

\title{
Tensiometric and Phase Domain Behavior of Lung Surfactant on Mucus-Like Viscoelastic Hydrogels
}

\author{
Daniel M. Schenck ${ }^{1}$ and Jennifer Fiegel ${ }^{1,2,{ }^{*}}$ \\ ${ }^{1}$ Department of Pharmaceutical Sciences and Experimental Therapeutics, The University of lowa, \\ lowa City, IA, 52242, USA \\ ${ }^{2}$ Department of Chemical and Biochemical Engineering, The University of lowa, lowa City, IA, \\ 52242, USA
}

\section{Abstract}

Lung surfactant has been observed at all surfaces of the airway lining fluids and is an important contributor to normal lung function. In the conducting airways, the surfactant film lies atop a viscoelastic mucus gel. In this work, we report on the characterization of the tensiometric and phase domain behavior of lung surfactant at the air-liquid interface of mucus-like viscoelastic gels. Poly(acrylic acid) hydrogels were formulated to serve as a model mucus with bulk rheological properties that matched those of tracheobronchial mucus secretions. Infasurf® (Calfactant), a commercially available pulmonary surfactant derived from calf lung extract, was spread onto the hydrogel surface. The surface tension lowering ability and relaxation of Infasurf films on the hydrogels was quantified and compared to Infasurf behavior on an aqueous subphase. Infasurf phase domains during surface compression were characterized by fluorescence microscopy and phase shifting interferometry. We observed that increasing the bulk viscoelastic properties of the model mucus hydrogels reduced the ability of Infasurf films to lower surface tension and inhibited film relaxation. A shift in the formation of Infasurf condensed phase domains from smaller, more spherical domains to large, agglomerated, multilayer structures was observed with increasing viscoelastic properties of the subphase. These studies demonstrate that the surface behavior of lung surfactant on viscoelastic surfaces, such as those found in the conducting airways, differs significantly from aqueous, surfactant-laden systems.

\section{Graphical Abstract}

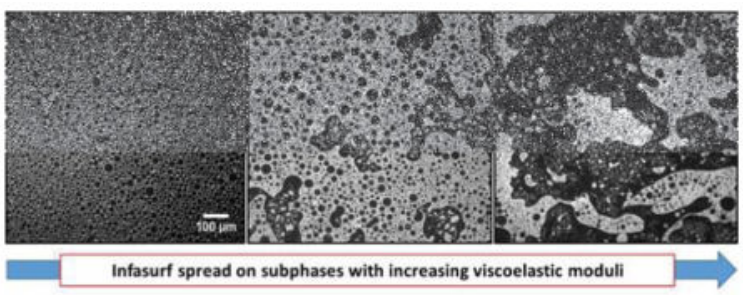

"To whom correspondence should be addressed: Jennifer Fiegel, The University of Iowa, 4133 Seamans Center for the Engineering Arts and Sciences, Iowa City, IA, 52242, USA. jennifer-fiegel@uiowa.edu.

Supporting Information. Viscoelastic moduli of Carbopol hydrogels before and after Infasurf addition. 


\section{Keywords}

bulk rheology; conducting airways; fluorescence microscopy; hydrogel; lung surfactant; mucus; surface tension; domain morphology

\section{INTRODUCTION}

Lining the entirety of the lung epithelium, the airway lining fluids serve to hydrate and protect the underlying tissue. These fluids function as dynamic semipermeable barriers that allow the exchange of gases, nutrients and water, but limit the transport of foreign material to the epithelium ${ }^{1}$. The structure of the fluids plays an important role in their functionality. In the conducting airways, the airway lining fluid develops as a thick ( 10-30 $\mu \mathrm{m}$ in the tracheobronchial region) multi-phase fluid. The periciliary fluid layer coats the epithelial surface and is occupied by cilia that extend from the cell surface to the mucus gel and facilitate mucociliary clearance. The mucus gel layer lying atop the periciliary layer is composed of a complex network of macromolecules, including cross-linked glycoproteins ${ }^{2}$ and proteins, as well as ions and water. Due to its network structure, the mucus layer exhibits viscoelastic behavior in response to external deformation. Rheological measurements of tracheobronchial mucus demonstrate its elastic behavior at physiological shear rates (breathing) and a shear thinning viscosity profile $\mathrm{e}^{3-4}$. The viscoelastic properties of mucus are important for maintaining function in the conducting airways, as the mucus gel acts to entrap foreign particles for the protection of the underlying epithelium and facilitates the continuing function of the mucociliary escalator through energy storage ${ }^{5}$.

At the air-fluid interface of the airways, lung surfactant adsorbs to the fluid interface and appears as a distinguishable, mostly continuous surface layer observed in various animals $^{6-7}$. Lung surfactant reduces the surface tension of the airway fluids from $\sim 30-34$ $\mathrm{mN} / \mathrm{m}$ in the trachea ${ }^{8}$ to $<10 \mathrm{mN} / \mathrm{m}$ in the alveoli ${ }^{9}$. The surfactant layer in the alveoli has been widely studied for its ability to ensure normal respiration mechanics ${ }^{10}$. Likewise, the functional characteristics of conducting airway surfactant have been connected to airway stabilization and maintenance of unobstructed airways ${ }^{11-12}$, and host defense through antibacterial/antiviral activity ${ }^{7}$ and the displacement of foreign material into the mucus gel to be cleared through mucociliary clearance ${ }^{13}$. Due to the functional importance of lung surfactant, changes in the surface tension of airway fluids have been linked to various pathological states, including respiratory distress syndrome, chronic bronchitis, cystic fibrosis, atelectatic human lung, and asthma ${ }^{14}$.

Alveolar surfactant has been widely studied due to its role in respiration and link to respiratory distress syndrome. However the surface tension behavior of the conducting airway surfactant has been largely ignored despite its importance in lung health and disease. Thus the current study was designed to quantify the surface tension lowering and relaxation behavior of lung surfactant on mucus-like, viscoelastic fluids. We hypothesized that the viscoelastic properties of the subphase would suppress surface tension evolution of lung surfactant films during compression and relaxation compared to a watery subphase. Model conducting airway mucus gels were developed using neutralized poly(acrylic acid) 
hydrogels, which allowed easy tuning of bulk viscoelastic properties to match those of native, healthy conducting airway mucus. Infasurf ${ }^{\circledR}$, a commercially available pulmonary surfactant derived from calf lungs, was chosen as the model surfactant due to its similarity in composition to the conducting airway surfactant. Upon spreading Infasurf at the hydrogel surface, surface tensiometric studies were conducted during continuous compression to monitor the effect of subphase on surface tension lowering and with step-wise compression to monitor surface tension relaxation over time. Fluorescence microscopy studies were performed to visualize and quantify phase domain formation during compression.

\section{MATERIALS AND METHODS}

\subsection{Materials}

Carbopol (poly(acrylic acid)) grade 971P NF was kindly donated by Lubrizol Advanced Materials (Cleveland, $\mathrm{OH}$ ). Sodium hydroxide, $2 \mathrm{~N}$ solution, was purchased from Fisher (Fairlawn, NJ). All water used during experimentation was obtained from a NANOpure II system (Barnstead International, Dubuque, IA) with an $18.1 \mathrm{M} \Omega$-cm resistivity. Infasurf ${ }^{\circledR}$ (Calfactant, lot \#89512070) served as the model lung surfactant for these experiments and was kindly donated by ONY Inc. (Amherst, NY). Chloroform was purchased from SigmaAldrich (St. Louis, MO) and methanol (99.9\% purity, ACS grade) was purchased from RPI (Mt. Prospect, IL). The fluorescent probe Texas-Red-1,2-dihexadecanoyl-sn-glycero-3phosphoethanolamine (Texas Red-DHPE) was purchased from Invitrogen (Carlsbad, CA).

\subsection{Carbopol hydrogel formulation}

Given the difficulty in obtaining large quantities of native tracheobronchial mucus from healthy human subjects and the inherent variability in the rheological properties of native mucus $^{3}$ and mucin-based gels ${ }^{15}$, we used hydrogels to mimic the bulk rheological properties of native mucus. Synthetic viscoelastic hydrogels can be produced in large quantities with a high degree of repeatability and can be easily modified to alter physical properties. In the current work, poly(acrylic acid) (Carbopol) was chosen due to their high purity, ability to maintain batch-to-batch reproducibility, variety of available commercial grades, and ease of altering their bulk viscoelastic properties. Carbopol has been previously investigated as a model mucus system ${ }^{16}$, a synergistic rheology modifier ${ }^{17}$, and a base for surfactant spreading studies ${ }^{18}$. Carbopol exhibits a net negative charge similar to mucin fibers ${ }^{19}$. Therefore, the charge interactions of mucin-based mucus gels and Carbopol hydrogels are anticipated to be similar. However these hydrogels do not match the ionic or protein composition of native mucus, thus limiting their potential use when interactions with these components are significant.

Carbopol hydrogels were neutralized to $\mathrm{pH} 7.4$ to achieve their maximum viscosity in solution, with a $2 \mathrm{~N} \mathrm{NaOH}$ solution serving as the neutralizing agent at a ratio of $4 \mathrm{~mL} / \mathrm{g}$ Carbopol. One liter batches of neutralized Carbopol hydrogels were prepared at concentrations of $0.025 \%, 0.03 \%, 0.04 \%$, and $0.05 \%$ in purified water with the appropriate amount of $2 \mathrm{~N} \mathrm{NaOH}(0.4 \mathrm{~mL} / 100 \mathrm{mg}$ Carbopol) mixed in prior to Carbopol addition. The gels were mixed using stir bars on a stir plate for 24 hours at room temperature $\left(-23-25^{\circ} \mathrm{C}\right)$ at which point a clear and dispersed hydrogel was obtained. 


\subsection{Infasurf solution preparation}

Infasurf, an extract of natural surfactant from calf lungs suspended in $0.9 \%$ aqueous $\mathrm{NaCl}$ solution, was chosen to modify the surface tension of the model mucus due to its similarity in composition to conducting airway surfactant $(\mathrm{CAS})^{20-21}$. The composition of CAS is closely represented by pulmonary surfactant generated from Type II cells in the alveoli ${ }^{22-23}$. From the alveolar spaces, pulmonary surfactant is carried up the airways due to the surface tension gradient and the mucociliary escalator ${ }^{22,24}$. Local production and release of phospholipids by tracheal epithelial cells ${ }^{25-26}$ and the submucosal glands of both human tracheal and bronchial biopsy specimens ${ }^{27}$ have also been detected, thus both sources likely contribute to airway surfactant composition. While evidence pertaining to the origin of the CAS points to both alveolar and local sources ${ }^{12,28}$, recent studies suggest that alveolar surfactant represents the largest proportion of $\mathrm{CAS}^{22-23}$. CAS phospholipids, quantified by analysis of raw tracheal aspirates, are composed of approximately $72-80 \%$ phosphatidylcholine (PC) and 33-45\% dipalmitoylphosphatidylcholine (DPPC), with smaller amounts of phosphatidylglycerol (PG, 3-4\%), phosphatidylethanolamine (PE, 12$15 \%$ ), phosphatidylinositol (PI, 3-5\%), and sphingomyelin (SPH, 2-4\%) present ${ }^{22-23}$. Infasurf is composed of similar phospholipids as CAS, with 84\% PC, 29-45\% DPPC, 4-6\% PG, 3-4\% PE, 2-5\% PI, and 1-2\% SPH ${ }^{21}$. Additionally, Infasurf contains approximately $6 \%$ neutral lipids (primarily cholesterol and free fatty acids) and $~ 2 \%$ proteins (including surfactant associated proteins SP-B and SP-C, which have been observed in tracheal aspirates $^{29-30}$ ). According to the package insert, $1 \mathrm{~mL}$ of Infasurf contains roughly $35 \mathrm{mg}$ of phospholipids (PL) of which $26 \mathrm{mg}$ is phosphatidylcholine and $16 \mathrm{mg}$ is dipalmitoylphosphatidylcholine, $0.7 \mathrm{mg}$ of proteins including $0.26 \mathrm{mg}$ of surfactant protein$\mathrm{B}$, and other neutral lipids. Independent studies have identified the presence of cholesterol at approximately $1.7 \mathrm{mg} / \mathrm{mL}$, surfactant protein-C, and small amounts of free fatty acids and triglycerides ${ }^{21}$. While similar in composition to CAS, Infasurf is missing SP-A (found in $\mathrm{CAS}^{22}$ ), contains smaller amounts of $\mathrm{PE}$ and sphingomyelin, and contains more $\mathrm{PC}^{22}$. The hydrophilic surfactant associated proteins SP-A and SP-D are removed from Infasurf during the extraction process. In the current study, Infasurf spreading solutions were made by dissolving freshly vortexed Infasurf in a 90:10\% v/v chloroform:methanol co-solvent to obtain a final PL concentration of $1.0 \mathrm{mg} / \mathrm{mL}$ in solution. Further mention of Infasurf solution will refer to this $1.0 \mathrm{mg}$ PL/mL solution as it is the solution that is spread onto the subphases in this study.

\subsection{Carbopol hydrogel characterization}

2.4.1. Bulk rheology of Carbopol hydrogels-Pulmonary mucus is a shear thinning, viscoelastic fluid whose bulk viscoelastic moduli have been measured to be in the range of $0.2-32 \mathrm{mN} / \mathrm{m}$ for the storage modulus $\left(\mathrm{G}^{\prime}\right)$ and $1-13 \mathrm{mN} / \mathrm{m}$ for the loss modulus $\left(\mathrm{G}^{\prime \prime}\right)$ at 1 $\mathrm{rad} / \mathrm{s}$ and $10-52 \mathrm{mN} / \mathrm{m}$ for the storage modulus $\left(\mathrm{G}^{\prime}\right)$ and $7-63 \mathrm{mN} / \mathrm{m}$ for the loss modulus $\left(\mathrm{G}^{\prime \prime}\right)$ at $100 \mathrm{rad} / \mathrm{s}^{2-3,31-32}$. Carbopol hydrogels with bulk rheological properties that match those of native mucus were identified by rheological testing and analysis under oscillatory shear deformation. An oscillating cone-and-plate rheometer, the Haake Rheostressl (Thermo Scientific, Nashville, TN), was used to measure the viscoelastic moduli, $\mathrm{G}^{\prime}$ and $\mathrm{G}^{\prime \prime}$, and the loss factor, $\tan \delta$, of the Carbopol hydrogels. Oscillation testing was performed at room 
temperature $\left(22-23^{\circ} \mathrm{C}\right)$ using a 60 -mm-diameter, $4^{\circ}$ angle, stainless steel conical plate at a gap distance of $0.14 \mathrm{~mm}$ with $4 \mathrm{~mL}$ gel samples. Stress amplitude sweeps were performed at $1 \mathrm{~Hz}$ from $0.01-1.1 \mathrm{~Pa}$ to identify the linear viscoelastic region (LVR). Within the LVR, the gel response to an applied shear stress is independent of the magnitude of deformation and thus is indicative of the structural properties of the gel. Based on these experiments, a shear stress of $0.10 \mathrm{~Pa}$ was chosen for subsequent frequency sweep experiments for all gels investigated. Frequency sweeps were performed to determine the viscoelastic moduli by applying an oscillating shear stress to the gels over a range of frequencies from $0.5-105$ $\mathrm{rad} / \mathrm{s}$. The storage modulus $\left(\mathrm{G}^{\prime}\right)$, an indicator of elastic behavior, and the loss modulus $\left(\mathrm{G}^{\prime \prime}\right)$, an indicator of viscous behavior, were determined from the resulting stress-strain curves using equations (1) and (2)

$$
\begin{aligned}
& G^{\prime}=\frac{\sigma_{0}}{\varepsilon_{0}} \cos \delta \\
& G^{\prime \prime}=\frac{\sigma_{0}}{\varepsilon_{0}} \sin \delta
\end{aligned}
$$

where $\sigma_{\mathrm{o}}$ and $\varepsilon_{\mathrm{o}}$ represent the stress and strain amplitudes, respectively, and $\delta$ represents the phase shift or the delayed strain response to the applied shear stress. Lastly the loss factor $\tan \delta$, the ratio of the loss to elastic moduli was calculated by equation ( 3 ),

$$
\tan \delta=G^{\prime \prime} / G^{\prime}
$$

with a $\tan \delta<1$ indicating a more elastic gel $\left(\mathrm{G}^{\prime}\right.$ dominates gel behavior) and a $\tan \delta>1$ indicating a more viscous gel $\left(\mathrm{G}^{\prime \prime}\right.$ dominates gel behavior).

To ensure the Carbopol hydrogels maintained rheological stability over the course of the experiments, $0.04 \%$ gels were stored over a 1 month period at room temperature in glass beakers with parafilm covering to limit evaporation. Bulk rheological testing was conducted to determine the short-term rheological stability of the Carbopol gels.

\subsubsection{Bulk rheology of Carbopol gels containing surfactant-As a complex} surfactant/protein mixture, some components of Infasurf are expected to penetrate into the Carbopol gels rather than remain at the surface, which could alter the gel structure and thus their viscoelastic properties. To ensure that the addition of Infasurf to the Carbopol gels did not affect their bulk rheological properties, the moduli of $0.025 \%$ and $0.04 \%$ gels with and without Infasurf added were determined. Fifty $\mu \mathrm{L}$ of the organic Infasurf solution $(1 \mathrm{mg}$ $\mathrm{PL} / \mathrm{mL}$ concentration) was added to $35 \mathrm{~mL}$ of the $0.025 \%$ and $0.04 \%$ gels, representing the maximum amount of Infasurf solution that would be spread onto a gel surface throughout these experiments. After this Infasurf addition, the gel was mixed for 1 hour on a rotator and then analyzed to determine the gel viscoelastic moduli using the cone-and-plate rheometer at 
room temperature. Comparisons between the viscoelastic moduli, $\mathrm{G}^{\prime}$ and $\mathrm{G}^{\prime \prime}$, of the gels before and after interaction with Infasurf were performed.

\subsection{Tensiometric studies of Infasurf-laden hydrogels}

\subsubsection{Infasurf compression isotherms on water and Carbopol hydrogels-}

Tensiometry is a sensitive and precise method to measure the surface tension of a fluid. Surface tension versus surface area isotherms provide critical information about the phases and phase transitions of surfactant molecules at the surface. We were interested in compression isotherms as lung surfactant is compressed as it travels up the airways due to the significant decrease in surface area as it travels up the conducting airways ${ }^{33}$. In these studies we report the tensiometric data as surface pressure, the change in surface tension compared to the native surface. Surface pressure versus surface area $(\pi-\mathrm{A})$ compression isotherms of Infasurf films on water or Carbopol gel subphases $(0.025 \%$ and $0.04 \%)$ were generated at room temperature using a Langmuir-Wilhelmy balance (Minitrough System 4, KSV NIMA, Finland). The system consisted of a polytetrafluoroethylene (PTFE) coated trough $\left(782 \mathrm{~mm} \times 75 \mathrm{~mm} \times 5 \mathrm{~mm}\right.$, surface area $=558 \mathrm{~cm}^{2}$, subphase volume $\left.=250 \mathrm{~mL}\right)$, equipped with two Delrin (polyoxymethylene) barriers for symmetric compression, and a force transducer connected to a platinum Wilhelmy plate (perimeter $=39.24 \mathrm{~mm}$, width $=$ $19.62 \mathrm{~mm}$, height $=10 \mathrm{~mm}$ ). The Delrin barriers have been shown to prevent leakage under the barriers during compression ${ }^{34}$. The trough was filled with $250 \mathrm{~mL}$ of Carbopol gel and was given time to spread at the surface. The Wilhelmy plate was placed perpendicular to the surface and approximately $1 \mathrm{~mm}$ into the subphase, then zeroed to enable direct measurement of the surface pressure. Infasurf $(65 \mu \mathrm{L}$, corresponding to a surface concentration of $0.12 \mu \mathrm{g} \mathrm{PL} / \mathrm{cm}^{2}$ ) was evenly deposited onto the subphase surface using a 50 $\mu \mathrm{L}$ Hamilton microsyringe and the solvent allowed to evaporate for $20 \mathrm{~min}$ prior to surface pressure measurement. The surface was then compressed from $558 \mathrm{~cm}^{2}$ (maximum area with the barriers in place) to $50 \mathrm{~cm}^{2}$ at a rate of $15.4 \mathrm{~cm}^{2} / \mathrm{min}(2.7 \% / \mathrm{min})$. The surface pressure was recorded and displayed by the Layer Builder software (KSV NIMA, Finland). The $\pi$-A isotherms were analyzed in Microsoft Excel to determine the initial delay in surface pressure rise (the lift-off point), the surface pressure and surface area where the plateau region first appears ( $\pi_{\text {plateau }}$, representing the beginning of the monolayer to multilayer transition region), and the surface pressure and surface area of film collapse $\left(\pi_{\text {collapse }}\right)$.

The two-dimensional compressibility of the Infasurf films was calculated from the compression isotherms. Compressibility $\left(\mathrm{C}_{\mathrm{m}}\right)$ is the inverse of the compression modulus, a rheological quantity related to the monolayer rigidity and an indicator of steric interactions between the surfactant molecules. A region of high compressibility indicates a surfactant with a relatively large amount of surface area available per molecule to compress into; conversely, a region of low compressibility indicates a saturated or partially saturated surface. Compressibility was calculated every 10 seconds during the compression process using equation (4):

$$
C_{m}=-\frac{1}{A} \times\left(\frac{d A}{d \pi}\right)
$$


where $\mathrm{A}$ is the surface area and $\pi$ is the surface pressure.

\subsubsection{Surface tension relaxation of Infasurf films on water and Carbopol}

subphases-Surface tension relaxation studies provide information about surface rheological properties and are used to quantify the viscoelastic resistance to surfactant rearrangement and the stability of surface tensions after compression at an air-liquid interface $^{35}$. The relaxation of Infasurf films from surface tensions of $30-34 \mathrm{mN} / \mathrm{m}$, values that mimic the surface tension of the mammalian trachea ${ }^{8}$, and $~ 22-27 \mathrm{mN} / \mathrm{m}$, the equilibrium surface tension that has been reported for lung surfactant ${ }^{36}$, was evaluated on $0.025 \%$ and $0.04 \%$ Carbopol gels. Step-wise surface compressions ${ }^{35,37}$ were performed to determine the effect of gel Carbopol content $(0.025 \%$ and $0.04 \%)$ on the relaxation of the Infasurf films after compression to a surface tension of $30-34 \mathrm{mN} / \mathrm{m}$ and $\sim 22 \mathrm{mN} / \mathrm{m}$. To perform surface compressions, $35 \mathrm{~mL}$ of water or Carbopol gel was filled into a small PTFE-coated Langmuir trough (195 mm x $50 \mathrm{~mm}$ x $4 \mathrm{~mm}$, surface area $\left.98 \mathrm{~cm}^{2}\right)(\mathrm{KSV}$ NIMA, Finland). Two Delrin barriers were then positioned at the trough edges so that an initial surface area of $85 \mathrm{~cm}^{2}$ was obtained and the platinum Wilhelmy plate was used to record surface tensions. Infasurf solutiofn volumes of $10 \mu \mathrm{L}\left(\mathrm{C}_{0}=0.12 \mu \mathrm{g} \mathrm{PL} / \mathrm{cm}^{2}\right)$ were spread on the subphases using a $50 \mu \mathrm{L}$ Hamilton microsyringe. After 10 min to allow surfactant spreading and solvent evaporation, compression of the surface was performed by sliding both barriers $1 \mathrm{~cm}$ inward (a $10 \mathrm{~cm}^{2}$, or $12 \%$ surface area reduction) over a $10 \mathrm{sec}$ period (compression rate $=1 \mathrm{~cm}^{2} / \mathrm{sec}$ or $1.2 \% / \mathrm{sec}$ ). Surface tensions were recorded every minute for $10 \mathrm{~min}$, at which point the barriers were compressed an additional $1 \mathrm{~cm}$ inward and the surface tensions were once again recorded over $10 \mathrm{~min}$. Measurements were taken at 7 compression positions corresponding to $0,12,24,36,47,59$, and $71 \%$ surface area compression.

\subsection{Fluorescence Microscopy}

To determine the effect of the viscoelastic properties of the subphases on the phase domains of Infasurf during surface compression, fluorescence imaging was performed at room temperature. The Infasurf solution was doped with Texas Red-DHPE for enhanced contrast as the dopant fluoresces in the liquid phase and is excluded from the condensed phase. Thus, the condensed phase Infasurf appears black in fluorescent images. To visualize the Infasurf phase domains during compression, a $\mathrm{C}_{0}=0.12 \mu \mathrm{g} \mathrm{PL} / \mathrm{cm}^{2}$ surface film of the doped Infasurf was compressed on $0.025 \%$ and $0.04 \%$ Carbopol hydrogels and on water (see section 2.5.2 for details). Fluorescence microscopy images were obtained with a 10x objective using an Olympus BX 51 fluorescence enabled light microscope (Tokyo, Japan). Imaging was performed using a filter with an emission range of 573-648 nm, allowing for the observation of Texas Red-DHPE fluorescence. The fluorescence images were analyzed using ImageJ to determine the fraction of fluorescing and non-fluorescing surface. This analysis allowed for the quantification of condensed (non-fluorescing) phase at the air-liquid interface as a function of surface tension and subphase viscoelastic moduli. Images were converted to binary, and the number of black and white pixels quantified. At least eight images were analyzed at each compression position. 


\subsection{Surface topography}

The surface topography of an Infasurf-laden hydrogel was visualized using a 3D Optical Profiling System (WYKO NT1100, Veeco, Tuscon, AZ). The optical profiling system uses phase-shifting interferometry (PSI) to measure height differences at the interface at subnanometer vertical resolution and generates 3-D maps of the surface. Imaging was performed using a 20x objective and a 0.5 field of vision providing a vertical resolution of $0.1 \mathrm{~nm}$ and a lateral resolution of $750 \mathrm{~nm}$. The surface topography of Infasurf films on the $0.04 \%$ Carbopol model mucus hydrogel was visualized after the deposition of $10 \mu \mathrm{L}$ of Infasurf onto the gel surface $\left(\mathrm{C}_{0}=0.12 \mu \mathrm{g} \mathrm{PL} / \mathrm{cm}^{2}\right)$ at $0 \%$ compression in the small PTFE trough.

\section{RESULTS}

\subsection{Carbopol hydrogel characterization}

3.1.1. Bulk rheology of Carbopol hydrogels-The viscoelastic properties of the gels were tuned by altering the concentration of Carbopol in the formulation, providing a flexible system on which to study surfactant behavior. Carbopol hydrogels of concentrations from $0.025-0.05 \%$ demonstrated frequency-dependent viscoelastic moduli, with an increase in both the storage $\left(\mathrm{G}^{\prime}\right)$ and loss $\left(\mathrm{G}^{\prime \prime}\right)$ modulus observed as the frequency increased from $0.5-$ $105 \mathrm{rad} / \mathrm{s}$ (Figure 1A, 1B). This increase was gradual for all gels between 0.5 and $10 \mathrm{rad} / \mathrm{s}$ and is a trend observed in rheological studies of native tracheobronchial mucus ${ }^{3,38}$. At 10 $\mathrm{rad} / \mathrm{s}$, a sharp increase in both $\mathrm{G}^{\prime}$ and $\mathrm{G}^{\prime \prime}$ was observed that continued up to frequencies of $105 \mathrm{rad} / \mathrm{s}$, accompanied with significant variability. This erratic behavior from $10 \mathrm{rad} / \mathrm{s}$ and higher is indicative of the gel's inability to relax at high deformation frequencies leading to a breakdown in gel structure. This is a common behavior observed for semi-flexible polymer networks ${ }^{39}$ and mucus simulants ${ }^{40}$. The frequency dependent viscoelastic moduli were dependent on the percentage of Carbopol in the hydrogels and an increase in both $\mathrm{G}^{\prime}$ and $\mathrm{G}$ " was observed with increasing Carbopol content. The $\mathrm{G}^{\prime}$ and $\mathrm{G}^{\prime \prime}$ values for the $0.03 \%$, $0.04 \%$, and $0.05 \%$ gels were within the ranges reported for native, healthy, tracheobronchial mucus samples over the majority of the frequencies ${ }^{31}$, as represented by the dashed boxes in Figure 1. Higher Carbopol content gels than those studied here may be utilized as models of diseased tracheobronchial mucus (i.e. cystic fibrosis ${ }^{4}$ or COPD).

At low frequency ( $1 \mathrm{rad} / \mathrm{s})$, the loss factor tan $\delta$ decreased with increasing Carbopol content (Figure 1C). The lower Carbopol concentration gels $(0.025 \%-0.04 \%)$ exhibited more liquid-like hydrogel behavior with $\tan \delta>1$, whereas the $0.05 \%$ hydrogels exhibited more solid-like behavior with a $\tan \delta<1$ and $\mathrm{G}^{\prime}$ almost double that of $\mathrm{G}^{\prime \prime}$. As frequency increased up to about $10 \mathrm{rad} / \mathrm{s}, \tan \delta$ for all the hydrogels decreased slightly. A gel point was observed at $5.5,3$, and $1 \mathrm{rad} / \mathrm{s}$ for the $0.025 \%, 0.03 \%$, and $0.04 \%$ gels, respectively, occurring at lower frequencies as the Carbopol content increased. The $0.05 \%$ gel remained in a gel state throughout the entire frequency range (Figure 1D).

3.1.2. Bulk rheological stability of Carbopol hydrogels-The bulk rheological stability of the $0.04 \%$ Carbopol hydrogel was monitored over a 1 month period. During this time, a reduction in the viscoelastic moduli of the hydrogels was observed (Figure 2), with G 
' at $1 \mathrm{rad} / \mathrm{s}$ decreasing by $27.6 \pm 10.0 \%$ after 2 weeks and by $27.9 \pm 3.3 \%$ after 4 weeks. Likewise, $\mathrm{G}^{\prime \prime}$ at $1 \mathrm{rad} / \mathrm{s}$ decreased by $31.6 \pm 2.9 \%$ after 2 weeks and $38.3 \pm 0.7 \%$ after 4 weeks. Applying a $\pm 10 \%$ threshold for rheological stability, gels displayed stable viscoelastic properties for up to one week of storage. This decrease in moduli was expected as a result of the slow dissociation of neutralization ions from the gel network, as suggested by Tamburic and colleagues ${ }^{41}$. Based on this result, all further studies were conducted with gels within 1 week of initial formulation.

Hydrogel viscoelastic properties were also analyzed before and after mixing with the organic Infasurf solution. The gels exhibited no significant changes in viscoelastic moduli after the addition of Infasurf (Table S1, Supporting Information). These similarities of gel rheology before and after Infasurf addition were observed across all frequencies tested, confirming that the surfactant solution did not modify the bulk rheology of the subphase in this study.

\subsection{Tensiometric analysis of Infasurf-laden hydrogels}

3.2.1. Surface tension of bare Carbopol hydrogels-Given the high water content of the Carbopol hydrogels and that Carbopol is not surface active, surface tension values of the bare gels were expected to be close to that of pure water $(\sim 72 \mathrm{mN} / \mathrm{m})$. Indeed, the initial surface tensions of the bare Carbopol hydrogels were not significantly different as a function of Carbopol concentration, with gel surface tensions of $72.33 \pm 0.12 \mathrm{mN} / \mathrm{m}, 71.63 \pm 0.23$ $\mathrm{mN} / \mathrm{m}$, and $71.77 \pm 0.37 \mathrm{mN} / \mathrm{m}$ recorded for the $0.025 \%, 0.04 \%$, and $0.05 \%$ hydrogels, respectively.

\subsubsection{Infasurf compression isotherms on water and Carbopol hydrogels-}

Infasurf compression isotherms on the water subphase consisted of four distinguishable regions (Figure 3 ) that were similar to those observed in previous studies ${ }^{36,42-43}$. At large surface areas $\left(558 \mathrm{~cm}^{2}\right.$ to $\left.350 \mathrm{~cm}^{2}\right)$, a steady rate of surface pressure rise was observed, representing compression of the liquid-expanded (LE) phase and condensed phase Infasurf which coexist in the Infasurf monolayer ${ }^{42,44}$. As compression continued, the condensed phase grew at the expense of the LE phase. Zhang and colleagues have demonstrated by AFM imaging and topographical analysis that the condensed phase domains of Infasurf consist of a core of titled condensed (TC) phase enveloped by a cholesterol-rich liquid ordered (LO) phase, forming a domain-in-domain structure ${ }^{36,44}$. Analysis of the composition of the condensed phase of BLES films (a cholesterol containing, bovine derived lung surfactant similar to Infasurf) by Harbottle et al. ${ }^{45}$ demonstrated through time of flight secondary ion mass spectroscopy (ToF-SIMS) that the TC microdomains consist of disaturated phospholipids (mostly DPPC) while the surrounding LE phase consisted of primarily unsaturated PLs. The liquid and condensed phases of Infasurf on the water subphase coexist throughout the compression up to $40 \mathrm{mN} / \mathrm{m}\left(\pi_{\text {plateau }}\right)$ at which point a plateau in the isotherm was observed. This plateau region is indicative of a refinement of the monolayer resulting in the exclusion of the more fluid-like and unsaturated lipids in the LE and LO phases $^{36}$ from the interfacial monolayer ${ }^{36,42,44,46-47}$ into three-dimensional multilayer reservoirs ${ }^{48-49}$. Further compression to surface pressures of $45-50 \mathrm{mN} / \mathrm{m}$ completes the refinement of the Infasurf monolayer in our studies, resulting in the creation of a phospholipid enriched interface. When further compressed, a sharp increase in surface 
pressure similar to that observed upon compression of TC phase phospholipids, was observed. The surface pressure continued to increase upon compression until the Infasurf film collapsed at a surface pressure of about $59 \mathrm{mN} / \mathrm{m}\left(\pi_{\text {collapse }}\right)$. This collapse pressure was lower than values presented in other studies $(\sim 66-70 \mathrm{mN} / \mathrm{m})^{42-44}$, which may be a result of lot to lot variation in Infasurf composition ${ }^{50}$ or may be indicative of leakage at the barriers at high compression.

We hypothesized that the viscoelastic properties of the subphase would alter the surface tension behavior (compression and relaxation) of CAS compared to a watery subphase. With increasing Carbopol content in the subphase and thus increasing viscoelastic properties, significant alterations in the $\pi-A$ isotherm were observed (Figure 3 ). Whereas the compression isotherm of Infasurf on water had four clearly defined regions with distinct and sharp transitions, the compression isotherms of Infasurf on Carbopol gels demonstrated a smoothing out of the phase transitions. Increasing the subphase Carbopol content led to a decrease in surface pressures throughout the compression process. This resulted in a lower plateau pressure ( $\pi_{\text {plateau }}$ decreased from $40.0 \pm 0.8 \mathrm{mN} / \mathrm{m}$ on the water to $38.0 \pm 0.4$ and $36.0 \pm 0.5 \mathrm{mN} / \mathrm{m}$ on the $0.025 \%$ and $0.04 \%$ Carbopol gels, respectively) and lower collapse pressure ( $\pi_{\text {collapse }}$ decreased from $59 \pm 1.71 \mathrm{mN} / \mathrm{m}$ on water to $51 \pm 1.05$ and $47.5 \pm 0.68$ $\mathrm{mN} / \mathrm{m}$ on the $0.025 \%$ and $0.04 \%$ Carbopol gels, respectively) with increasing Carbopol content. In addition, a delay in the lift-off point and surface areas at which the plateau and collapse regions began were observed. The surface area where surface pressure is first generated, i.e. the lift-off point, corresponds to the minimal surface density at which surfactant molecules begin to interact. Delays in the lift-off point of 10 and $58 \mathrm{~cm}^{2}$ were observed for compressed Infasurf on the $0.025 \%$ and $0.04 \%$ gels when compared to Infasurf on water. Thus, greater compression was required to initiate molecule interaction on Carbopol subphases. This delay in molecular interaction persists throughout compression as observed with the delay in $\pi_{\text {plateau }}$ and $\pi_{\text {collapse. }}$ To ensure that Carbopol is not surface active and thus itself altering the surface tension isotherms, pure solvent (no surfactant) was added to the surface of the $0.04 \%$ gels, allowed to evaporate, and the surface compressed. A slight increase in surface pressure was observed at high compression beginning at a surface

area of $250 \mathrm{~cm}^{2}$, leading to a total increase in surface pressure of $6 \mathrm{mN} / \mathrm{m}$ which might have increased the collapse pressure of the higher Carbopol content gels. This increase in surface pressure is likely due to dragging of subphase up the Wilhelmy plate at high very high compression.

\subsubsection{Compressibility analysis of Infasurf monolayers on Carbopol hydrogels}

-To analyze the rigidity of the Infasurf films on the different subphases, the twodimensional compressibility $\left(\mathrm{C}_{\mathrm{m}}\right)$ of the Infasurf films was determined. Monolayer compressibility is the inverse of the compression modulus, and is a measure of the resistance of the condensing monolayer phases to compression ${ }^{51}$. Thus a high compressibility indicates a less rigid monolayer with a lower elasticity, and can be observed when the surfactant molecules encounter less resistance to compression, thus being a more 'compressible' surface film. Four distinct regions of compressibility were observed (Figure 4), supporting observations from Infasurf compressibility data from the literature ${ }^{36,43}$. In the gas and liquid expanded phase at low compression, large $\mathrm{C}_{\mathrm{m}}$ values are observed since the surfactant 
molecules experience minimal steric interactions with neighboring surfactant molecules.

Compressibility values within the region of $\mathrm{LE} /$ condensed phase co-existence on water $(\sim 0.01-0.02 \mathrm{~m} / \mathrm{mN})$ were similar to those reported for the pure Infasurf phospholipids ${ }^{52-53}$, suggesting that the majority of surface pressure alteration is due to the activity of phospholipids at the air-liquid interface. The baseline compressibility values were larger on the $0.04 \%$ gels $(\sim 0.03-0.04 \mathrm{~m} / \mathrm{mN})$ than on water. High compressibility was again observed as a peak during the monolayer to multilayer transition region (plateau), where the squeezeout of non-phospholipid components likely occurs ${ }^{36}$. The maximum compressibility during this squeeze-out region decreased with increasing Carbopol content $(0.18,0.14$ and 0.12 $\mathrm{m} / \mathrm{mN}$ for Infasurf on water, 0.04\% Carbopol gel, and 0.025\% Carbopol gel, respectively), and occurred at lower surface pressures $(43.5 \mathrm{mN} / \mathrm{m}$ for Infasurf on water, $37.0 \mathrm{mN} / \mathrm{m}$ for Infasurf on $0.04 \%$ Carbopol gel, and $39.6 \mathrm{mN} / \mathrm{m}$ for Infasurf on $0.025 \%$ Carbopol gel). After squeeze-out, a drop in $\mathrm{C}_{\mathrm{m}}$ values was observed, indicating compression of the refined phospholipid-rich film.

3.2.4. Surface tension relaxation of Infasurf laden surfaces-To achieve and maintain stable surface tensions that correlated to values reported for the tracheobronchial region of the lungs $(\sim 30-34 \mathrm{mN} / \mathrm{m})$ and near the equilibrium surface tension for lung surfactant ( $22 \mathrm{mN} / \mathrm{m}$ ), Infasurf was compressed and maintained at a series of designated compression ratios on water and two Carbopol hydrogels. The short-term surface tension relaxation of the compressed Infasurf films was monitored by holding the barriers at a constant surface area for 10 minutes (Figure 5). Although complete relaxation of the Infasurf films on the Carbopol hydrogels to stable surface tensions was not observed within the time frame investigated, the influence of subphase viscosity/elasticity on the relaxation of surface tension (increasing values after compression) was observed. Over 10 minutes, the surface tension of the $32 \mathrm{mN} / \mathrm{m}$ Infasurf films rose by $2.8 \pm 0.1 \mathrm{mN} / \mathrm{m}(8.6 \pm 0.03 \%)$ when on water, but only by $0.96 \pm 0.26 \mathrm{mN} / \mathrm{m}(2.9 \pm 0.8 \%)$ on $0.025 \%$ Carbopol gels. Thus increasing subphase viscoelastic properties led to inhibited film relaxation and higher surface tension stability. On the $0.04 \%$ Carbopol gels, the surface tension fell slightly by $0.08 \pm 0.14 \mathrm{mN} / \mathrm{m}$ $(0.24 \pm 0.42 \%$ decrease) over 10 minutes, suggesting minimal film relaxation and significant surface tension stability with the most viscoelastic subphase. Similar observations were made for the surface tension relaxation of the $\sim 22 \mathrm{mN} / \mathrm{m}$ Infasurf films, with surface tensions rising by $3.5 \pm 0.46 \mathrm{mN} / \mathrm{m}(15.6 \pm 3.4 \%), 1.6 \pm 0.12 \mathrm{mN} / \mathrm{m}(7.1 \pm 1.1 \%)$, and 1.9 $\pm 0.33 \mathrm{mN} / \mathrm{m}(7.9 \pm 1.2 \%)$ over $10 \mathrm{~min}$ on water, $0.025 \%$ and $0.04 \%$ Carbopol hydrogels, respectively. Wustneck et al. ${ }^{35}$ observed similar relaxation of surface tensions throughout step-wise compression of DPPC monolayers on water, with surface tension values slowly decreasing over a few hours to a steady value. Given the long relaxation times of lung surfactant molecules on water, it is not surprising that complete relaxation was not observed over the 10 minutes time frame used in the current study. We anticipate that over time (hours) the system would completely relax while still demonstrating a dependency on subphase viscosity/elasticity.

\subsection{Fluorescence microscopy and surface topography}

The addition of a fluorescently-labeled lipid to Infasurf enabled the liquid and condensed phase domains to be visualized by fluorescence microscopy. In these experiments, the liquid 
phases of Infasurf fluoresced while the condensed phase Infasurf excluded the fluorescence dye and appeared black in the images. Compression of Infasurf films on water led to an increase in condensed phase at the surface (Figure 6A). The shapes of the condensed domains on water were homogenous and circular, appearing as small black dots with diameters of $\sim 4 \mu \mathrm{m}$ at $0 \%$ compression and $\sim 12 \mu \mathrm{m}$ at $59 \%$ compression similar to values reported by Zhang et al ${ }^{44}$. Phase inversion occurred at $59 \%$ compression, where the percentage of condensed phase exceeded the percentage of liquid expanded phases. Compression of Infasurf on the $0.025 \%$ Carbopol hydrogel demonstrated similar behavior, with an increase in non-fluorescing condensed phase observed as the compression proceeded (Figure 6B). While the majority of the discernable condensed phases on the Carbopol gel were circular, non-circular condensed phase domains were also observed with increasing surface compression. Additionally, the size of these phase domains was less homogenous, with diameters ranging from $4-15 \mu \mathrm{m}$ at $0 \%$ compression and 4-35 $\mu \mathrm{m}$ and larger at 59\% compression. Infasurf on the $0.04 \%$ Carbopol hydrogel exhibited similar increases in condensed phase with increasing compression, though the domains appeared as both circular depots and as large asymmetrical agglomerates (Figure 6C). Before any barrier compression was performed, the larger of these amorphous phase domains measured up to $150 \mu \mathrm{m}$ wide. The aggregated condensed phase domains grew larger with compression until they dominated the field of vision at 59\% compression. Similar observations of phase domain morphology was made in a study by Anseth et $\mathrm{a}^{54}$, where the condensed phase domains of Infasurf became increasingly amorphous and forming agglomerate-like structures following a gelation of the surfactant (due to exposure to pollution), suggesting that the gel-like properties of the surface dictated the morphologies of the phase domains. Additionally, we have demonstrated in previous studies a similar relationship between subphase viscoelastic properties and phase domain formation of DPPC monolayers at the air-liquid interface of a mucin-based mucus mimetic subphase ${ }^{15}$. Condensed phase domains of DPPC monolayers were observed as small spherical domains on low viscosity mucin solutions, but became aggregated and relatively amorphous when imaged on cross-linked (high viscosity) mucin solutions. This provides evidence that the phase domain changes we observed with Infasurf on Carbopol hydrogels occur on all surfaces that exhibit viscoelastic behavior.

The percentage of condensed phase Infasurf on each of the three subphases was quantified by image analysis (Figure 7). As compression progressed, the percentage of condensed phase increased. At 59\% compression, the slope of the $\%$ condensed phase increased faster with compression due to phase inversion at this point. At the highest compression ratio of $71 \%$, the surface largely consisted of non-fluorescing condensed phase $(77.3 \pm 5.6 \%)$, with small amounts of fluorescence still visible. The remaining fluorescence detected at $71 \%$ compression did not represent a distinct liquid expanded phase, rather consisting of fluorescing lipid that had been excluded from the monolayer. No significant differences in $\%$ condensed phase at a given compression position on water, $0.025 \%$, and $0.04 \%$ Carbopol hydrogels were observed (Figure 7A). However, when plotting \% condensed phase against the surface tension, the amount of condensed phase Infasurf was significantly larger at a given surface tension on the $0.04 \%$ gel than on both the $0.025 \%$ gel and on water (Figure 7B), demonstrating the importance of gel viscoelasticity on modulating condensed phase domain formation. 
The surface topography of an Infasurf film on the $0.04 \%$ Carbopol hydrogel $\left(\mathrm{C}_{0}=0.12 \mu \mathrm{g}\right.$ $\mathrm{PL} / \mathrm{cm}^{2}$ ) demonstrated a difference in phase domain height between condensed phase Infasurf and the surrounding LE phase Infasurf (Figure 8), similar to results (though not shape and size) obtained by AFM methods by Zhang et $\mathrm{al}^{44}$. In these images, dark blue represents the baseline height and green and red represent surface protrusions. It is observed that the surface was not of uniform height. The Infasurf condensed phase domains were typically $\sim 1-5 \mathrm{~nm}$ higher than the surrounding LE phase, although irregular peaks were observed within the domains with heights reaching up to $10 \mathrm{~nm}$. This range of protrusion heights suggests the presence of multilayers of Infasurf lipids within the condensed phase aggregates. Future studies would benefit from additional surface topography characterization of these aggregates at greater magnification to differentiate between condensed phase Infasurf and Infasurf multilayers.

\section{DISCUSSION}

In this study, we aimed to quantify the surface tension lowering and relaxation behavior of lung surfactant on mucus-like, viscoelastic hydrogels. We hypothesized that the viscoelastic properties of the subphase would alter the surface tension behavior of lung surfactant compared to a watery subphase. Our results demonstrate that increasing subphase viscoelastic properties leads to surface pressure reduction during compression, limits surface tension relaxation, and results in more stable surfactant films. We also observed the formation of amorphous, multilayered condensed phase domains that were inhomogeneously distributed on the hydrogel surfaces.

Increased subphase viscosity and elasticity have been linked to the inhibition of surfactant mobility (both molecular and bulk droplet) at the air-liquid interface. Surfactant mobility at the interface is modulated by both surface tension gradients and surface diffusion of individual molecules which generally promote a homogeneous distribution of surfactant across the surface. This is because surfactant in localized regions of high concentration will migrate towards regions of the surface with low surfactant concentration to minimize surface tension and surface concentration gradients ${ }^{55}$. Through mathematical modeling ${ }^{56-57}$ and experimental observations ${ }^{15,31,58}$ it has been demonstrated that subphases with high viscous or elastic properties resist spreading forces due to surface tension gradients (Marangom forces) and in some cases, may inhibit spreading entirely due to a yield stress barrier ${ }^{56,58}$. The reduced ability to rearrange locally high concentrations of surfactant can result in nonhomogeneous distribution of surfactant on the surface and lead to the formation of 3D multilayer domains. Such multilayer domains have been observed in in vitro studies of pulmonary surfactant analogues ${ }^{59-61}$ and at the air/mucus interface in the conducting airways of rats ${ }^{62}$. In the current study, we observed dramatic differences in surfactant domain formation on viscoelastic hydrogel subphases compared to a water subphase. On water, uniform formation of small, condensed domains was observed across the entire film surface before compression and grew evenly with compression. Previous AFM studies of these domains have demonstrated that these small condensed phase domains coexist at the surface with surrounding LE phase, and illustrate that these domains serve as sites for nucleation and condensed phase growth as the surface becomes more compressed ${ }^{36,44}$. On the hydrogel surfaces, large aggregates of condensed phase domains were observed even 
before compression and the condensed phase grew irregularly throughout compression.

Surface topographical images demonstrated variable heights across a single domain and the film heights across the condensed domains indicated multilayer formation. This multilayer formation results in surfactant being withheld from the surface. With a lower surface concentration, more surface compression would thus be needed for the surfactant molecules to interact. In the current study this was observed as a shift in the isotherm to the left, leading to a delayed lift-off point, plateau, and collapse.

In addition to a left-hand shift in the $\pi$-A isotherms, we also observed a flattening of the isotherm, resulting in more gentle phase transitions. Similarly, Wiegart, et al. ${ }^{63}$ demonstrated with DPPC films on subphases of increasing viscoelasticity both a reduction in the surface pressure of LE/TC phase transitions and a decrease in the sharpness of phase transitions as monitored by $\pi_{\text {plateau. }}$. They attributed these results to inhomogeneous condensation of the surface film which results in a reduction in the sharpness of phase transitions as different regions of the film experience phase transitions at different times. Similar results have been observed in other studies as well, where $\pi$-A isotherms of surfactant monolayers on viscous subphases have a similar shape to those on water subphases, yet lower surface pressure values are reported ${ }^{64,65}$. Limiting the ability of high concentrations of condensed phase to locally rearrange has been demonstrated to inhibit surface tension relaxation ${ }^{35}$. Our studies support this, as we observed slower relaxation of the films on the hydrogel surfaces. We anticipate that given enough time (on the order of hours based on comparable relaxation studies ${ }^{35,37}$ ), complete molecular rearrangement of the Infasurf films would occur and surface pressures would ultimately rise to steady values. Future relaxation studies over longer time periods would enable quantification of relaxation times and insight into the molecular mechanisms underlying the relaxation process ${ }^{35}$.

In their studies, Wiegart, et al. point to a potential combination of bulk viscoelastic properties and DPPC interactions with the subphase on the modulation of surface pressure. Ionic attraction ${ }^{66}$, hydrophobic bonding ${ }^{66}$, and hydrogen bonding ${ }^{67}$ between Carbopol and soluble surfactants have been observed in the literature and have demonstrated the ability to influence surface tension, though these studies involved the characterization of Carbopol/ surfactant dispersions with the surfactant mixed into the Carbopol (Gibbs' monolayers) rather than deposited onto the surface (Langmuir monolayers). In our studies, the addition of Infasurf into the Carbopol gels did not result in bulk rheological changes, which indicates that adsorption of Infasurf onto Carbopol fibers did not occur ${ }^{67-68}$. However, we have not ruled out other Carbopol/Infasurf interactions that could contribute to the altered surface tension behavior of Infasurf films, thus further investigation of this is warranted in future studies.

An alternative theory to explain the shifts observed in the $\pi$-A isotherms during Infasurf compression on Carbopol gels is a dissipation in compressive energy at the surface by the viscoelastic subphases. Viscoelastic inhibition to deformation may reduce the efficacy of barrier compression as viscoelastic gels can absorb a portion of the compression energy, reducing the external forces acting to promote the compression of the Infasurf film. The dissipation of energy from external deformations is a trait of viscoelastic materials and has been linked to the reduction in liquid droplet spreading at the air-liquid interface ${ }^{69}$ and the 
damping of surface waves with an increase in surface ${ }^{70}$ and/or bulk subphase ${ }^{65}$ viscosity. The result would be lower and delayed surface pressures upon compression compared to Infasurf on water, as has been observed in the current study.

Our demonstration that the surface tension behavior and domain formation of lung surfactant films is altered by subphase viscoelastic properties indicates that surfactant films in the conducting airways exhibit unique behavior compared to those on water subphases. This suggests that the surface tension gradient that exists between the alveolar and tracheobronchial mucus may be due, in part, to increasing resistance to surfactant mobility of the more viscoelastic mucus of the conducting airways. As a number of diseases that affect the conducting airways have been linked to changes in surface tension ${ }^{14}$, a better understanding of this surface tension behavior of lung surfactant could facilitate lung disease diagnosis and treatment. Further, the higher surface tensions and reduced surfactant transport associated with viscoelastic subphases may play a crucial role in the barrier function of tracheobronchial mucus, serving to reduce the ability of microorganisms and deposited aerosols to penetrate into the mucus or transport laterally across the surface.

\section{CONCLUSIONS}

Poly(acrylic acid) (Carbopol) hydrogels were formulated to mimic the viscoelastic properties of native, healthy, tracheobronchial mucus and Infasurf was spread on the surface to lower the surface tension to native values. The viscoelasticity of the subphase reduced the ability of the surfactant to lower surface tension during the compression process and inhibited relaxation after compression. This suggests either inhibition of surfactant mobility at the air-liquid interface and/or dissipation of compressive energy at the surface by the hydrogel. The subphase viscoelasticity also delayed the appearance of phase transitions commonly associated with compression isotherms of pulmonary surfactant on water and resulted in larger, more amorphous condensed phases. Overall, these findings help clarify the behavior of complex lung surfactant on mucus-like subphases, demonstrating that the surface of this viscoelastic model mucus differs significantly from aqueous, surfactant-laden systems. This system will be useful for future studies focused on diagnosis and inhalation treatment of lung disease.

\section{Supplementary Material}

Refer to Web version on PubMed Central for supplementary material.

\section{Acknowledgments}

The authors would like to thank Dr. Amir Farnoud for helpful discussions concerning the compression isotherms. We also thank the University of Iowa's Central Microscopy Research Facility, a core resource supported by the Vice President for Research \& Economic Development, the Holden Comprehensive Cancer Center, and the Carver College of Medicine, for access to and training on the fluorescence microscope. We also thank the University of Iowa Microfabrication Facility (UIMF) for assistance with PSI operation for surface topography generation. Lastly, we would like to thank ONY Inc. for their generous donation of Infasurf and The Lubrizol Corporation for their kind donation of Carbopol. Funding for this work was provided by the National Institutes of Health (R21HL113876), the University of Iowa College of Pharmacy (D.S.), and the University of Iowa Graduate College (D.S.). 


\section{References}

1. Cone RA. Barrier Properties of Mucus. Adv Drug Delivery Rev. 2009; 61:75-85.

2. Yuan S, Hollinger M, Lachowicz-Scroggins ME, Kerr SC, Dunican EM, Daniel BM, Ghosh S, Erzurum SC, Willard B, Hazen SL, Huang XZ, Carrington SD, Oscarson S, Fahy JV. Oxidation Increases Mucin Polymer Cross-Links to Stiffen Airway Mucus Gels. Sci Transl Med. 2015; 7:1-9.

3. Lai SK, Wang YY, Wirtz D, Hanes J. Micro- and Macrorheology of Mucus. Adv Drug Delivery Rev. 2009; 61:86-100.

4. Tomaiuolo G, Rusciano G, Caserta S, Carciati A, Carnovale V, Abete P, Sasso A, Guido S. A New Method to Improve the Clinical Evaluation of Cystic Fibrosis Patients by Mucus Viscoelastic Properties. PLoS One. 2014; 9:1-13.

5. Lethem MI. The Role of Tracheobronchial Mucus in Drug Administration to the Airways. Adv Drug Delivery Rev. 1993; 11:271-298.

6. Geiser M, Kreyling WG. Deposition and Biokinetics of Inhaled Nanoparticles. Part Fibre Toxicol. 2010; 7:1-17. [PubMed: 20180970]

7. Gehr P, Green FH, Geiser M, Im Hof V, Lee MM, Schurch S. Airway Surfactant, a Primary Defense Barrier: Mechanical and Immunological Aspects. J Aerosol Med. 1996; 9:163-181. [PubMed: 10163349]

8. Gehr P, Schurch S, Berthiaume Y, Im Hof V, Geiser M. Particle Retention in Airways by Surfactant. J Aerosol Med. 1990; 3:27-43.

9. Schurch S, Bachofen H, Weibel ER. Alveolar Surface Tensions in Excised Rabbit Lungs: Effect of Temperature. Respir Physiol. 1985; 62:31-45. [PubMed: 4070835]

10. Zuo YY, Veldhuizen RA, Neumann AW, Petersen NO, Possmayer F. Current Perspectives in Pulmonary Surfactant--Inhibition, Enhancement and Evaluation. Biochim Biophys Acta. 2008; 1778:1947-1977. [PubMed: 18433715]

11. Liu MY, Wang LM, Li E, Enhorning G. Pulmonary Surfactant Will Secure Free Air-Flow through a Narrow Tube. J Appl Physiol. 1991; 71:742-748. [PubMed: 1938748]

12. Hohlfeld J, Fabel H, Hamm H. The Role of Pulmonary Surfactant in Obstructive Airways Disease. Eur Respir J. 1997; 10:482-491. [PubMed: 9042653]

13. Schurch S, Gehr P, Im Hof V, Geiser M, Green F. Surfactant Displaces Particles toward the Epithelium in Airways and Alveoli. Respir Physiol. 1990; 80:17-32. [PubMed: 2367749]

14. Fathi-Azarbayjani A, Jouyban A. Surface Tension in Human Pathophysiology and Its Application as a Medical Diagnostic Tool. BioImpacts. 2015; 5:29-44. [PubMed: 25901295]

15. Hamed, R. PhD Dissertation. University of Iowa; 2011. Development of a PhysiologicallyRelevant in Vitro System to Study Exhaled Bioaerosols.

16. Shah AJ, Donovan MD. Formulating Gels for Decreased Mucociliary Transport Using Rheologic Properties: Polyacrylic Acids. AAPS PharmSciTech. 2007; 8:E48-E53.

17. Riley RG, Smart JD, Tsibouklis J, Dettmar PW, Hampson F, Davis JA, Kelly G, Wilber WR. An Investigation of Mucus/Polymer Theological Synergism Using Synthesised and Characterised Poly(Acrylic Acid)S. Int J Pharm. 2001; 217:87-100. [PubMed: 11292545]

18. Sharma R, Corcoran TE, Garoff S, Przybycien TM, Swanson ER, Tilton RD. Quasi-Immiscible Spreading of Aqueous Surfactant Solutions on Entangled Aqueous Polymer Solution Subphases. ACS Appl Mater Interfaces. 2013; 5:5542-5549. [PubMed: 23705869]

19. Li LD, Crouzier T, Sarkar A, Dunphy L, Han J, Ribbeck K. Spatial Configuration and Composition of Charge Modulates Transport into a Mucin Hydrogel Barrier. Biophys J. 2013; 105:1357-1365. [PubMed: 24047986]

20. Kahn MC, Anderson GJ, Anyan WR, Hall SB. Phosphatidylcholine Molecular Species of Calf Lung Surfactant. Am J Physiol. 1995; 269:L567-L573. [PubMed: 7491974]

21. Notter RH, Wang Z, Egan EA, Holm BA. Component-Specific Surface and Physiological Activity in Bovine-Derived Lung Surfactants. Chem Phys Lipids. 2002; 114:21-34. [PubMed: 11841823]

22. Bernhard W, Haagsman HP, Tschernig T, Poets CF, Postle AD, van Eijk ME, von der Hardt H. Conductive Airway Surfactant: Surface-Tension Function, Biochemical Composition, and Possible Alveolar Origin. Am J Respir Cell Mol Biol. 1997; 17:41-50. [PubMed: 9224208] 
23. Dushianthan A, Goss V, Cusack R, Grocott MPW, Postle AD. Phospholipid Composition and Kinetics in Different Endobronchial Fractions from Healthy Volunteers. BMC Pulm Med. 2014; 14:1-9. [PubMed: 24387157]

24. Rau GA, Dombrowsky H, Gebert A, Thole HH, von der Hardt H, Freihorst J, Bernhard W. Phosphatidylcholine Metabolism of Rat Trachea in Relation to Lung Parenchyma and Surfactant. J Appl Physiol. 2003; 95:1145-1152. [PubMed: 12909600]

25. Barrow RE. Chemical Structure of Phospholipids in the Lungs and Airways of Sheep. Respir Physiol. 1990; 79:1-8. [PubMed: 2309049]

26. Kim KC, Opaskar-Hincman H, Bhaskar KR. Secretions from Primary Hamster Tracheal Surface Epithelial Cells in Culture: Mucin-Like Glycoproteins, Proteoglycans, and Lipids. Exp Lung Res. 1989; 15:299-314. [PubMed: 2707187]

27. Girod S, Fuchey C, Galabert C, Lebonvallet S, Bonnet N, Ploton D, Puchelle E. Identification of Phospholipids in Secretory Granules of Human Submucosal Gland Respiratory Cells. J Histochem Cytochem. 1991; 39:193-198. [PubMed: 1987263]

28. Gehr P, Geiser M, Im Hof V, Schurch S, Waber U, Baumann M. Surfactant and Inhaled Particles in the Conducting Airways: Structural, Stereological, and Biophysical Aspects. Microsc Res Tech. 1993; 26:423-436. [PubMed: 8286788]

29. Simonato M, Baritussio A, Vedovelli L, Lamonica G, Carnielli VP, Cogo PE. Surfactant Protein B Amount and Kinetics in Newborn Infants: An Optimized Procedure. J Mass Spectrom. 2012; 47:1415-1419. [PubMed: 23147816]

30. Simonato M, Baritussio A, Pioselli B, Ori C, Catinella S, Carnielli VP, Cogo PE. Surfactant Protein C Metabolism in Human Infants and Adult Patients by Stable Isotope Tracer and Mass Spectrometry. Anal Bioanal Chem. 2014; 406:6225-6233. [PubMed: 25182966]

31. Hamed R, Fiegel J. Synthetic Tracheal Mucus with Native Rheological and Surface Tension Properties. J Biomed Mater Res, Part A. 2014; 102:1788-1798.

32. McCullagh CM, Jamieson AM, Blackwell J, Gupta R. Viscoelastic Properties of Human Tracheobronchial Mucin in Aqueous Solution. Biopolymers. 1995; 35:149-159. [PubMed: 7696561]

33. Lippmann M, Yeates DB, Albert RE. Deposition, Retention, and Clearance of Inhaled Particles. Br J Ind Med. 1980; 37:337-362. [PubMed: 7004477]

34. Hardy NJ, Richardson TH, Grunfeld F. Minimising Monolayer Collapse on Langmuir Troughs. Colloids Surf, A. 2006; 284:202-206.

35. Wustneck R, Wustneck N, Grigoriev DO, Pison U, Miller R. Stress Relaxation Behaviour of Dipalmitoyl Phosphatidylcholine Monolayers Spread on the Surface of a Pendant Drop. Colloids Surf, B. 1999; 15:275-288.

36. Zhang H, Wang YE, Fan Q, Zuo YY. On the Low Surface Tension of Lung Surfactant. Langmuir. 2011; 27:8351-8358. [PubMed: 21650180]

37. Klebanau A, Kliabanova N, Ortega F, Monroy F, Rubio RG, Starov V. Equilibrium Behavior and Dilational Rheology of Polyelectrolyte/Insoluble Surfactant Adsorption Films: Didodecyldimethylammonium Bromide and Sodium Poly(Styrenesulfonate). J Phys Chem B. 2005; 109:18316-18323. [PubMed: 16853357]

38. Bell AE, Allen A, Morris ER, Rossmurphy SB. Functional Interactions of Gastric Mucus Glycoprotein. Int J Biol Macromol. 1984; 6:309-315.

39. Koenderink GH, Atakhorrami M, MacKintosh FC, Schmidt CF. High-Frequency Stress Relaxation in Semiflexible Polymer Solutions and Networks. Phys Rev Lett. 2006; 96:138307-1-138307-4. [PubMed: 16712047]

40. Zahm JM, King M, Duvivier C, Pierrot D, Girod S, Puchelle E. Role of Simulated Repetitive Coughing in Mucus Clearance. Eur Respir J. 1991; 4:311-315. [PubMed: 1864345]

41. Tamburic S, Craig DQM. The Effects of Ageing on the Rheological, Dielectric and Mucoadhesive Properties of Poly(Acrylic Acid) Gel Systems. Pharm Res. 1996; 13:279-283. [PubMed: 8932449]

42. Alonso C, Bringezu F, Brezesinski G, Waring AJ, Zasadzinski JA. Modifying Calf Lung Surfactant by Hexadecanol. Langmuir. 2005; 21:1028-1035. [PubMed: 15667185]

43. Farnoud AM, Fiegel J. Calf Lung Surfactant Recovers Surface Functionality after Exposure to Aerosols Containing Polymeric Particles. J Aerosol Med Pulm Drug Delivery. 2015; 29:10-23. 
44. Zhang H, Fan QH, Wang YE, Neal CR, Zuo YY. Comparative Study of Clinical Pulmonary Surfactants Using Atomic Force Microscopy. Biochim Biophys Acta, Biomembr. 2011; 1808:1832-1842.

45. Harbottle RR, Nag K, McIntyre NS, Possmayer F, Petersen NO. Molecular Organization Revealed by Time-of-Flight Secondary Ion Mass Spectrometry of a Clinically Used Extracted Pulmonary Surfactant. Langmuir. 2003; 19:3698-3704.

46. Alonso C, Alig T, Yoon J, Bringezu F, Warriner H, Zasadzinski JA. More Than a Monolayer: Relating Lung Surfactant Structure and Mechanics to Composition. Biophys J. 2004; 87:41884202. [PubMed: 15454404]

47. Baoukina S, Roznnanov D, Mendez-Villuendas E, Tieleman DP. The Mechanism of Collapse of Heterogeneous Lipid Monolayers. Biophys J. 2014; 107:1136-1145. [PubMed: 25185549]

48. Watkins JC. The Surface Properties of Pure Phospholipids in Relation to Those of Lung Extracts. Biochim Biophys Acta. 1968; 152:293-306. [PubMed: 5639261]

49. Veldhuizen R, Nag K, Orgeig S, Possmayer F. The Role of Lipids in Pulmonary Surfactant. Biochim Biophys Acta, Mol Basis Dis. 1998; 1408:90-108.

50. Farnoud, AM. PhD Dissertation. University of Iowa; 2013. Interaction of Polymeric Particles with Surfactant Interfaces.

51. Vollhardt D, Fainerman VB. Progress in Characterization of Langmuir Monolayers by Consideration of Compressibility. Adv Colloid Interface Sci. 2006; 127:83-97. [PubMed: 17208192]

52. Gong K, Feng SS, Go ML, Soew PH. Effects of Ph on the Stability and Compressibility of Dppc/ Cholesterol Monolayers at the Air-Water Interface. Colloids Surf, A. 2002; 207:113-125.

53. Nowotarska SW, Nowotarski KJ, Friedman M, Situ C. Effect of Structure on the Interactions between Five Natural Antimicrobial Compounds and Phospholipids of Bacterial Cell Membrane on Model Monolayers. Molecules. 2014; 19:7497-7515. [PubMed: 24914896]

54. Anseth JW, Goffin AJ, Fuller GG, Ghio AJ, Kao PN, Upadhyay D. Lung Surfactant Gelation Induced by Epithelial Cells Exposed to Air Pollution or Oxidative Stress. Am J Respir Cell Mol Biol. 2005; 33:161-168. [PubMed: 15860796]

55. Koch K, Dew B, Corcoran TE, Przybycien TM, Tilton RD, Garoff S. Surface Tension Gradient Driven Spreading on Aqueous Mucin Solutions: A Possible Route to Enhanced Pulmonary Drug Delivery. Mol Pharmaceutics. 2011; 8:387-394.

56. Craster RV, Matar OK. Surfactant Transport on Mucus Films. J Fluid Mech. 2000; 425:235-258.

57. Gaver DP, Grotberg JB. The Dynamics of a Localized Surfactant on a Thin-Film. J Fluid Mech. $1990 ; 213: 127-148$.

58. Kaneko D, Gong JP, Zrinyl M, Osada Y. Kinetics of Fluid Spreading on Viscoelastic Substrates. J Polym Sci, Part B: Polym Phys. 2005; 43:562-572.

59. Bachofen H, Gerber U, Gehr P, Amrein M, Schurch S. Structures of Pulmonary Surfactant Films Adsorbed to an Air-Liquid Interface in Vitro. Biochim Biophys Acta. 2005; 1720:59-72. [PubMed: 16405864]

60. Ravasio A, Olmeda B, Bertocchi C, Haller T, Perez-Gil J. Lamellar Bodies Form Solid ThreeDimensional Films at the Respiratory Air-Liquid Interface. J Biol Chem. 2010; 285:28174-28182. [PubMed: 20558742]

61. Follows D, Tiberg F, Thomas RK, Larsson M. Multilayers at the Surface of Solutions of Exogenous Lung Surfactant: Direct Observation by Neutron Reflection. Biochim Biophys Acta. 2007; 1768:228-235. [PubMed: 17156743]

62. Sims DE, Horne MM. Heterogeneity of the Composition and Thickness of Tracheal Mucus in Rats. Am J Physiol: Lung Cell Mol Physiol. 1997; 273:L1036-L1041.

63. Wiegart L, Struth B, Tolan M, Terech P. Thermodynamic and Structural Properties of Phospholipid Langmuir Monolayers on Hydrosol Surfaces. Langmuir. 2005; 21:7349-7357. [PubMed: 16042465]

64. Weinbach SP, Kjaer K, Alsnielsen J, Lahav M, Leiserowitz L. Self-Assembled Langmuir Monolayers and Trilayers at the Air-Formamide Interface. J Phys Chem. 1993; 97:5200-5203.

65. Barraud A, Leloup J, Lesieur P. Monolayers on a Glycerol Subphase. Thin Solid Films. 1985; 133:113-116. 
66. Barreiro-Iglesias R, Alvarez-Lorenzo C, Concheiro A. Poly(Acrylic Acid) Microgels (Carbopol 934)/Surfactant Interactions in Aqueous Media Part Ii: Ionic Surfactants. Int J Pharm. 2003; 258:179-191. [PubMed: 12753764]

67. Barreiro-Iglesias R, Alvarez-Lorenzo C, Concheiro A. Poly(Acrylic Acid) Microgels (Carbopol 934)/Surfactant Interactions in Aqueous Media Part I: Nonionic Surfactants. Int J Pharm. 2003; 258:165-177. [PubMed: 12753763]

68. Milanovic M, Krstonosic V, Dokic L, Hadnadev M, Hadnadev TD. Insight into the Interaction between Carbopol 940 and Ionic/Nonionic Surfactant. J Surfactants Deterg. 2015; 18:505-516.

69. Shanahan MER, Carre A. Viscoelastic Dissipation in Wetting and Adhesion Phenomena. Langmuir. 1995; 11:1396-1402.

70. Stenvot C, Langevin D. Study of Viscoelasticity of Soluble Monolayers Using Analysis of Propagation of Excited Capillary Waves. Langmuir. 1988; 4:1179-1183. 

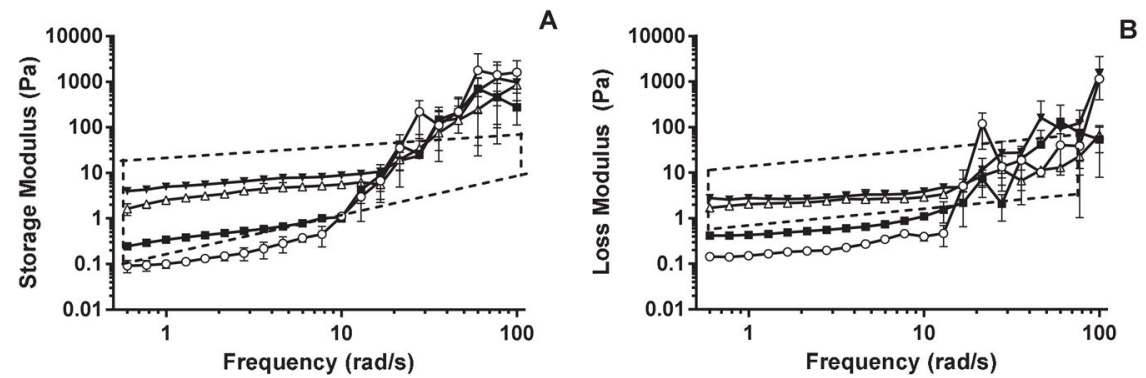

$\rightarrow 0.025 \%$ Carbopol Gel $\rightarrow 0.04 \%$ Carbopol Gel

$\rightarrow 0.03 \%$ Carbopol Gel $\rightarrow 0.05 \%$ Carbopol Gel

$\rightarrow 0.025 \%$ Carbopol Gel $\rightarrow 0.04 \%$ Carbopol Gel

$\rightarrow 0.03 \%$ Carbopol Gel $\rightarrow 0.05 \%$ Carbopol Gel
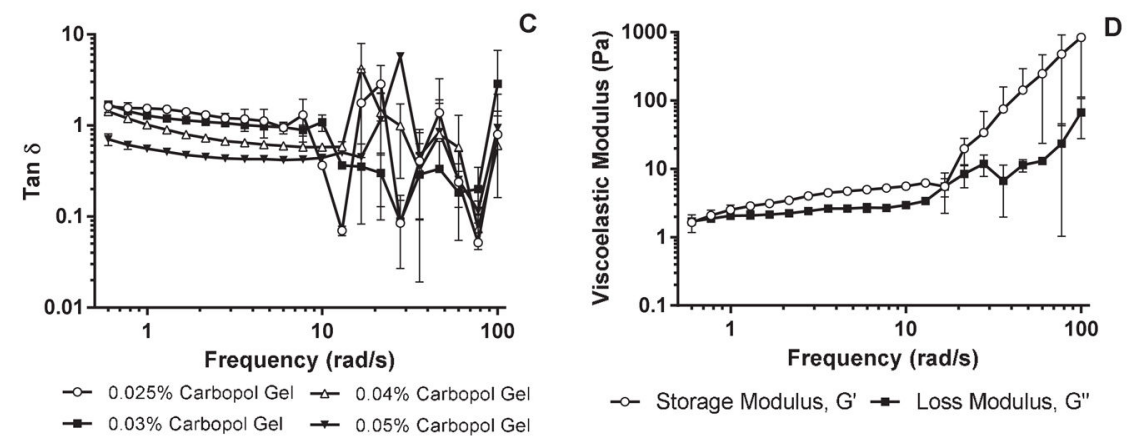

- Storage Modulus, G' $\rightarrow$ Loss Modulus, G"

Figure 1.

Frequency dependence of A) the storage modulus, B) the loss modulus, and C) $\tan \delta$ for neutralized Carbopol hydrogels of varying Carbopol content. Both $\mathrm{G}^{\prime}$ and $\mathrm{G}^{\prime \prime}$ for $\mathrm{D}$ ) the $0.04 \%$ Carbopol hydrogel are plotted together. The dashed boxes in 1A and 1B represent the range of viscoelastic modulus values for healthy, native tracheobronchial mucus obtained from literature that is the target for gel rheology. 


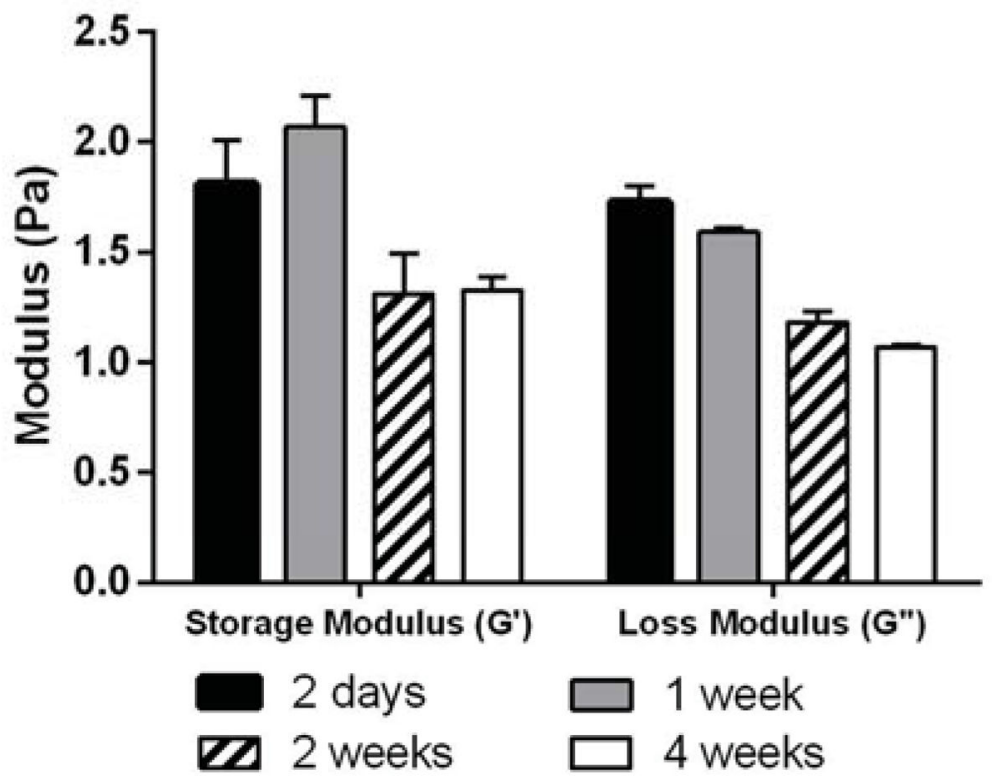

Figure 2.

Storage and loss modulus values for a $0.04 \%$ Carbopol hydrogel at 4 different time points post-mixing A decrease in $\mathrm{G}^{\prime}$ and $\mathrm{G}^{\prime \prime}$ is observed from 2 days to 2 weeks, though the difference in the viscoelasticity of the gels between 2 weeks and 4 weeks is statistically insignificant. 


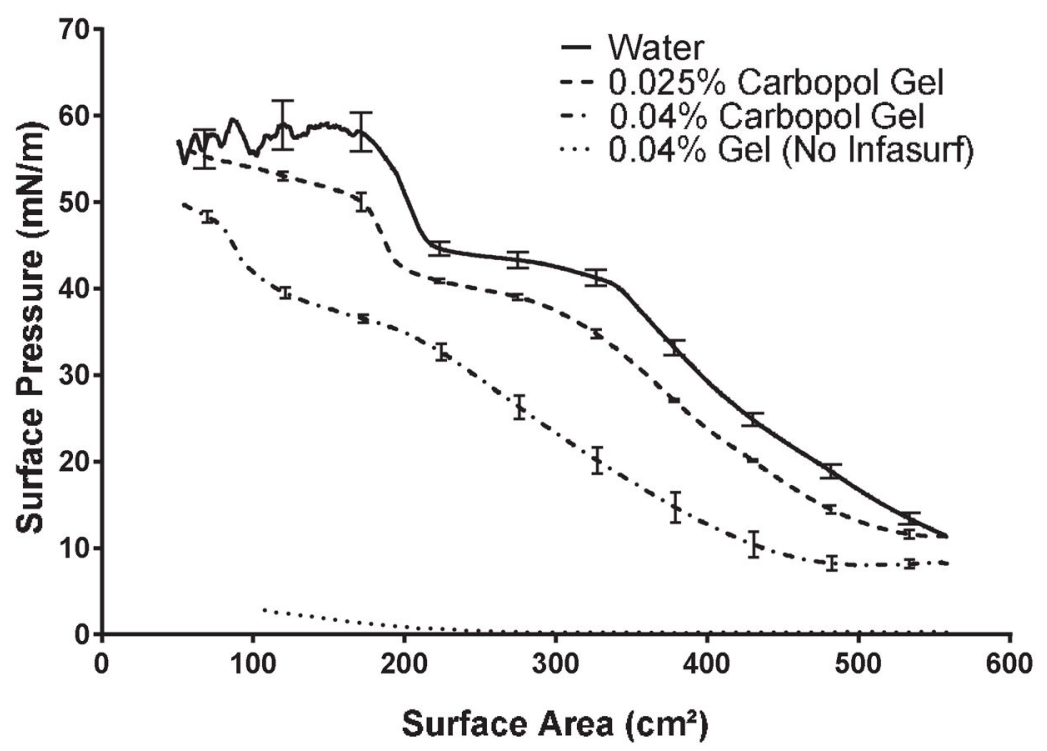

Figure 3.

Surface pressure versus surface area compression isotherms of Infasurf on water, $0.025 \%$, and $0.04 \%$ Carbopol gels and a compression of $0.04 \%$ Carbopol gel without Infasurf (control). In the cases where Infasurf was spread on the subphase surface, $65 \mu \mathrm{L}$ of the Infasurf solution was added to the surfaces $\left(\mathrm{C}_{0}=0.12 \mu \mathrm{g} \mathrm{PL} / \mathrm{cm}^{2}\right)$ before compression commenced at a rate of $15.4 \mathrm{~cm}^{2} / \mathrm{min}$. 


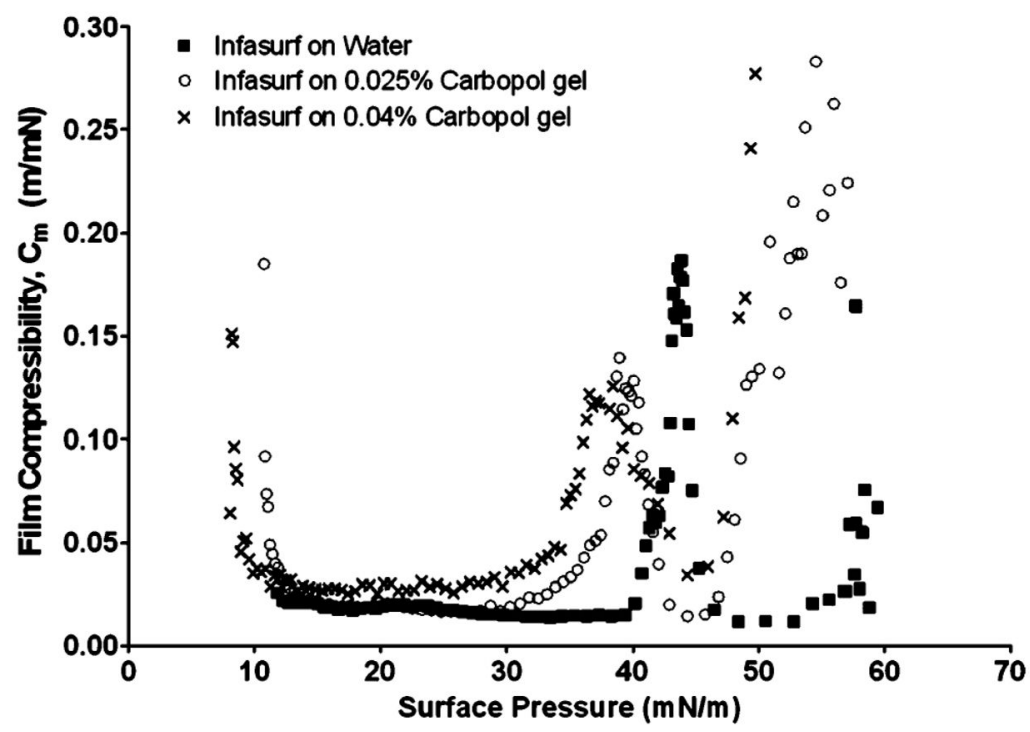

Figure 4.

The compressibility $(\mathrm{Cm})$ of Infasurf as a function of surface pressure on water and $0.025 \%$ and $0.04 \%$ Carbopol hydrogels. Each data set was calculated using compression isotherm data from Figure 3. 

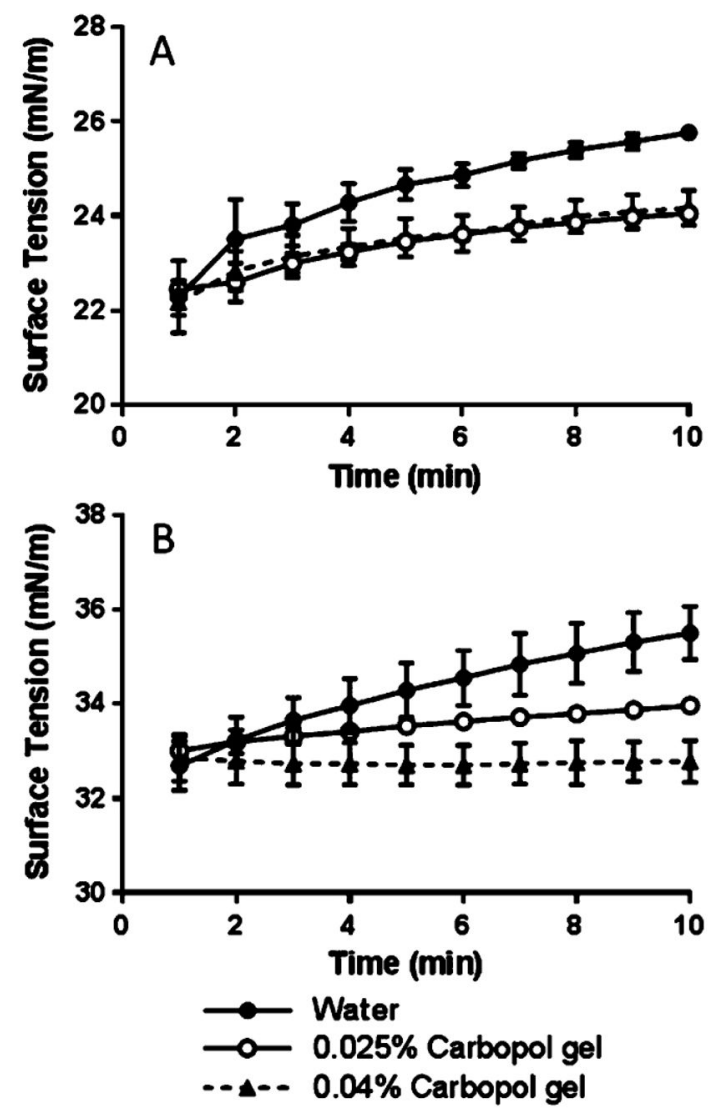

Figure 5.

Surface tensions as a function of time for Infasurf films $\left(\mathrm{C}_{0}=0.12 \mu \mathrm{g} \mathrm{PL} / \mathrm{cm}^{2}\right)$ on water and $0.025 \%$ and $0.04 \%$ Carbopol hydrogels compressed initially to (A) $\sim 22 \mathrm{mN} / \mathrm{m}$ and (B) $32-$ $33 \mathrm{mN} / \mathrm{m}$. The $\%$ rise in surface tension over $10 \mathrm{~min}$ is used as a measure of surface tension stability on each of the three subphases. The $32-33 \mathrm{mN} / \mathrm{m}$ starting point represents the surface tension in the tracheobronchial region, while the $\sim 22 \mathrm{mN} / \mathrm{m}$ starting point represents values similar to those reported for Infasurf equilibrium surface tension. 


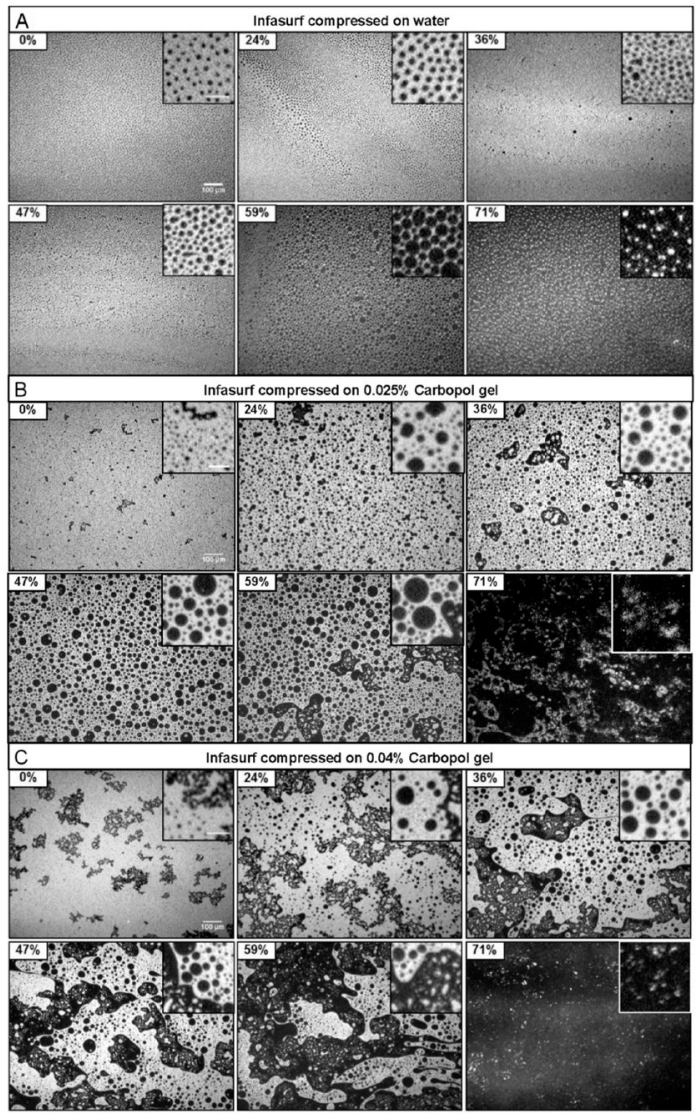

Figure 6.

Fluorescence images of compressed Infasurf monolayers $\left(\mathrm{C}_{0}=0.12 \mu \mathrm{g} \mathrm{PL} / \mathrm{cm}^{2}\right)$ on $\left.\mathrm{A}\right)$ water, B) $0.025 \%$ Carbopol, and C) $0.04 \%$ Carbopol hydrogel. The fluorescent lipid Texas Red-DHPE was added to Infasurf solutions to enable fluorescence imaging of phase domains. Bright $=$ Texas Red DHPE fluorescing in liquid phase, Dark $=$ non-fluorescing condensed phase. Percentages indicate \% compression from original surface area $\left(85 \mathrm{~cm}^{2}\right)$. Scale bar $=100 \mu \mathrm{m}($ Inset scale bar $=30 \mu \mathrm{m})$. 


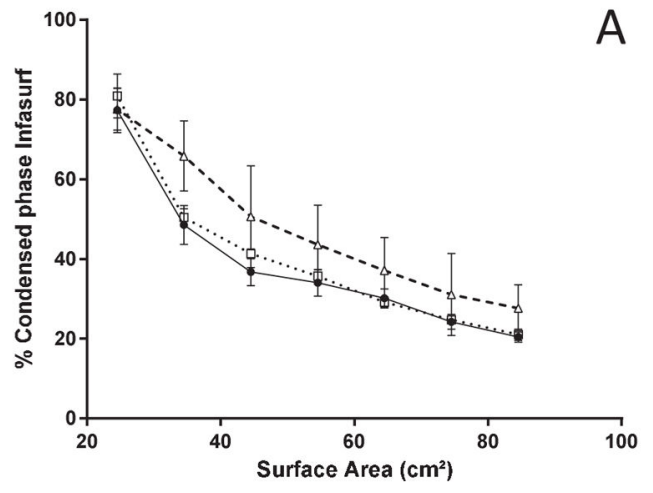

- Infasurf on water

๑. Infasurf on $0.025 \%$ Carbopol gel

$-\triangleleft \cdot$ Infasurf on $0.04 \%$ Carbopol gel

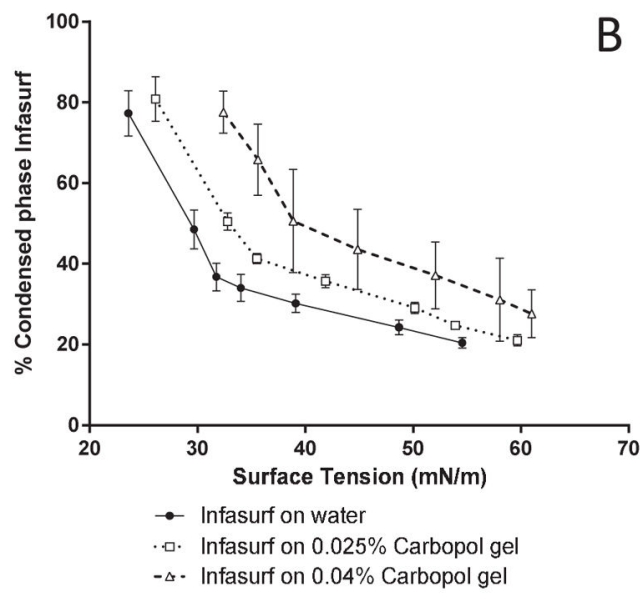

Figure 7.

Percent condensed phase of Infasurf on water and $0.025 \%$ and $0.04 \%$ Carbopol hydrogels as a function of $\mathrm{A})$ surface area and $\mathrm{B})$ surface tension $\left(\mathrm{C}_{0}=0.12 \mu \mathrm{g} \mathrm{PL} / \mathrm{cm}^{2}\right)$. From right to left, the data points correspond to $0,12,24,36,47,59$, and $71 \%$ compression. 

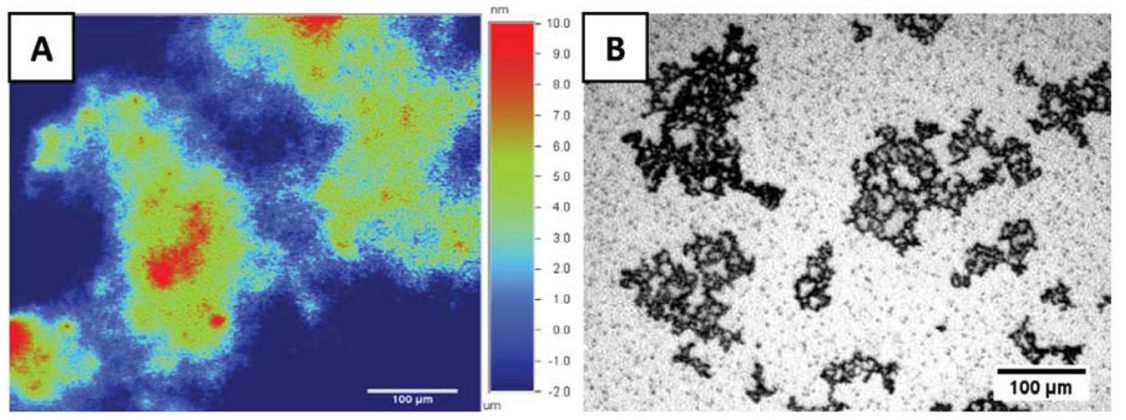

Figure 8.

(A) Phase shifting interferometry (PSI) image and (B) fluorescence microscopy image of Infasurf films $\left(\mathrm{C}_{0}=0.12 \mu \mathrm{g} \mathrm{PL} / \mathrm{cm}^{2}\right)$ spread on $0.04 \%$ Carbopol hydrogel at $0 \%$ compression. The legend to right of the PSI image represents the domain heights from a baseline value. Scale bars $=100 \mu \mathrm{m}$. 